\title{
Effects of Syrup Solution with Different Concentrations of Citric Acid on Quality and Storage Life of Canned Litchi
}

\author{
Nang Ngwe Chi Win ${ }^{1}$, Than Than Soe ${ }^{2}$, Abhijit Kar ${ }^{1}$, Yi Yi Soe ${ }^{3}$, Myat Lin ${ }^{1}$ \\ ${ }^{1}$ Department of Postharvest Technology, Advanced Center for Agricultural Research \& Education (ACARE), Yezin Agricultural \\ University, Naypyitaw, Myanmar \\ ${ }^{2}$ Department of Food Science and Technology, Yezin Agricultural University, Naypyitaw, Myanmar \\ ${ }^{3}$ Mawlamyine Campus, Yezin Agricultural University, Naypyitaw, Myanmar \\ Email: *july.237190@gmail.com
}

How to cite this paper: Win, N.N.C., Soe, T.T., Kar, A., Soe, Y.Y. and Lin, M. (2021) Effects of Syrup Solution with Different Concentrations of Citric Acid on Quality and Storage Life of Canned Litchi. Open Access Library Journal, 8: e8033.

https://doi.org/10.4236/oalib.1108033

Received: September 30, 2021

Accepted: October 23, 2021

Published: October 26, 2021

Copyright $\odot 2021$ by author(s) and Open Access Library Inc.

This work is licensed under the Creative Commons Attribution International License (CC BY 4.0).

http://creativecommons.org/licenses/by/4.0/

\begin{abstract}
Litchi fruit is a drupe or stone fruit. It is conical, heart-shaped or spherical with a thick leathery, indehiscent pericarp at maturity. Litchi is known for its pleasant flavour and juicy aril with attractive red colour pericarp. It is an excellent source of vitamins and minerals. Litchi fruits are generally eaten fresh because of their very short storage life and it ripens quickly, short production period and shelf life. Such fruit may be converted into value-added products such as juice, jelly, squash, canned litchi, nuts, and frozen litchi. The most common process to preserve litchi is canning. The aim of this study was to evaluate the quality and storage of canned litchi affected by syrup solution with different citric acid concentrations. The experiment was conducted at the laboratory of Postharvest Technology Department, ACARE, Yezin Agricultural University by using a randomized complete block design with four replications. The treatments were the litchi flesh and syrup which consisted of sucrose, distilled water without citric acid is treated as control and others are treated with citric acid $(0.2 \%$ and $0.4 \%)$ filled in a glass jar stored at room temperature. Data on total soluble solid, pulp firmness, pulp colour $\left(\mathrm{a}^{*}\right)$, total titratable acidity, $\mathrm{pH}$, total sugar, reducing sugar, non-reducing sugar, ascorbic acid, total phenolics content and microbial analysis were collected and analysed. The canned litchi slightly increased in pulp colour with a slightly decrease in $\mathrm{pH}$ value. The more the citric acid\% in canned litchi is, the more the pulp colour changed with the decrease in $\mathrm{pH}$ value along the storage periods is. There were no significant changes in total soluble solid and pulp firmness of canned litchi till the end of the storage. There was decreased in total sugar, non-reducing sugar and total titratable acidity. However, there
\end{abstract}


were increased in reducing sugar, ascorbic acid and total phenolics content. There was no occurrence of total viable count, yeasts and moulds in canned litchi throughout the storage periods.

\section{Subject Areas}

Food Science

\section{Keywords}

Litchi, Canning, Colour, Total Phenolics Content, pH, Quality

\section{Introduction}

Litchi (also called Lychee or Leechee) belongs to the family Sapindaceae. Litchi (Litchi chinensis Sonn.) is originated near southern China and northern Vietnam [1]. The fruit is grown commercially in many countries, including China, India, Thailand, Pakistan, Madagascar, Mauritius, Australia, South Africa and Israel which account for most of the fruit production [2]. After China, India and Vietnam rank as the second and third-largest producers, in 2017 [3].

Litchi fruit is a non-climacteric subtropical fruit with high commercial value for sweet-acidic taste, juicy, pleasant floral aroma which is surrounded by a reddish prickly leather-like skin and contains a shiny brown, usually large seed. Litchi pulp contains proteins, lipids, carbohydrates, vitamins (mainly Vitamin C, Vitamin B-complex) and phytonutrient flavonoids and minerals like manganese, magnesium, copper, iron, folate to name a few but amounts vary with the litchi variant [4] [5].

In general, litchi fruits are commonly eaten as fresh, and also can be consumed as other products like dried litchi, canned litchi, litchi honey, frozen litchi juice, nuts, squash, cordial, syrups, soft drink, wine, jam, jelly and concentrates [6] [7] [8] [9]. However, with a limited shelf life and its short production period, processed products such as canned litchi are mostly preserved.

Pink discolouration and texture are two important quality indices for canned litchi with the occurrence of the former always occurring simultaneously with degradation of texture [10]. Pink discolouration occurs in many canned fruit and vegetable products [11]. This phenomenon is not only of sensory importance but also leads to nutritional losses. Discolouration in canned litchi can be prevented with a $20{ }^{\circ}$ Brix syrup containing $0.1 \%-0.15 \%$ citric acid when boiled in water for less than $10 \mathrm{~min}$ [12]. Citric acid is an organic acid and it can be used as a food additive [13] to improve the acidity and flavour of foods, thereby improving the quality of preservation and preventing food spoilage [14]. Citric acid can also efficiently improve postharvest fruit quality, which has been proven in studies on apple and litchi [15] [16]. The use of citric acid in fresh-cut water chestnut can maintain its food quality and extend its shelf life [17]. Citric acid treatment can slow down the decrease in the soluble sugars and titratable acidity 
and is beneficial to maintain the fruit quality of Chinese jujube fruits during storage [18].

In order to maintain colour, texture and quality of canned litchi, the effect of citric acid content would be investigated in this study. Moreover, there was no preservation of fresh litchi by canning in Myanmar. Currently, canned litchis are mostly used imported products from China and Thailand. Thus, the objective of the study was to investigate the quality and storage of canned litchi affected by syrup solution with different citric acid concentrations.

\section{Materials and Methods}

\subsection{Experimental Site and Duration}

The experiment was conducted at the laboratory of the Department of Postharvest Technology, Advanced Center for Agricultural Research and Education (ACARE), Yezin Agricultural University, Naypyitaw, Myanmar from June to December, 2019.

\subsection{Procurement of Experimental Material}

Physiologically matured (135 - 140 days after flowering) litchi fruits were harvested from Naungmon village in Lashio Township at northern Shan State, Myanmar. After shipment, the fruits which were without any defects and uniform in shape, colour and size were selected. The fruits were precooled by air-dried prior to canning processing. The litchi fruits were canned according to the commercial process of the Royal Agriculture Company Ltd. (Chiangmai, Thailand).

\subsection{Procedure for Canning}

The fruits were peeled, destoned, and destined pulp (aril). After removing the seed, $120 \mathrm{~g}$ of litchi flesh were filled in sterilized glass jar and $175 \mathrm{~g}$ of syrup which consisted of $300 \mathrm{~g}$ sucrose, $700 \mathrm{~g}$ of distilled water were also prepared. Citric acid $(0.0,0.2 \%$ and $0.4 \%)$ were added according to the treatments, respectively. The filled cans were exhausted in steam for 6 minutes at $100^{\circ} \mathrm{C}$, then sealed, and sterilized in boiling water for 18 minutes and cooled down to $45^{\circ} \mathrm{C}$. All canned litchis were stored at room temperature prior to analysis. The data were evaluated at 15, 30, 60 and 90 days after storage.

\subsection{Quality Determination}

\subsubsection{Measurement of Total Soluble Solid, Pulp Firmness, Pulp Colour (a*), Total Titratable Acidity and $\mathrm{pH}$}

Total soluble solid of canned litchi was determined by squeezing the juice and measured by using RUDOLPH J47 automatic refractometer and the values were expressed in terms of degree Brix ( ${ }^{\circ}$ Brix). The pulp firmness of canned litchi was measured by using a digital Firmness Texture (TA.XT plus Texture Analyser) whereby each of five canned litchi pulps as a replicate was placed on a sample platform at a constant probe speed of $2 \mathrm{~mm} \cdot \mathrm{sec}^{-1}$ on two sides of the fruit. 
Firmness was measured based on millimeters of fruit deformation using $5 \mathrm{~mm}$ diameter cylinder probe which penetrates the pulp by $5 \mathrm{~mm}$. The mean value of each pulp of canned litchi puncture resistance was expressed as Newton (N) of force. The pulp colour changes $\mathbf{a}^{*}$ (red to green) of canned litchi was evaluated with a colorimeter (NR-20XE). The coordinate $\mathrm{a}^{\star}$ defines the deviation from the achromatic point corresponding to lightness, to red when it is positive and to green if negative. Two readings were taken using five canned litchi pulps from each treatment. Total titratable acidity of canned litchi was determined by the acid-base titration method [19]. The aliquot of $10 \mathrm{ml}$ of canned litchi aril was taken and diluted with distilled water and then titrated against $0.1 \mathrm{~N} \mathrm{NaOH}$ (sodium hydroxide) using 2 - 3 drops of phenolphthalein as an indicator so that the pink colour endpoint can be achieved. The titrated value was noted and total titratable acidity was calculated as citric acid equivalent according to the equation and expressed as a percentage. The $\mathrm{pH}$ value of canned litchi aril juice was measured by using an EC-40 $\mathrm{pH}$ meter.

\subsubsection{Measurement of Total Sugar}

Total sugar content in canned litchi was determined by Lane and Eynon method reported by [19]. The sample extract filtrate of $25 \mathrm{ml}$ was taken to which $2 \mathrm{ml}$ of concentrated hydrochloric acid $(\mathrm{HCl})$ was added and kept for hydrolyzation about 3 days at room temperature. The solution was neutralized with $1 \mathrm{~N} \mathrm{NaOH}$ solution using phenolphthalein as indicator and $\mathrm{HCl}$ was added into the solution till the colourless, finally the volume was made up to $100 \mathrm{ml}$. This extract solution was then titrated against Fehling's A and B solution as was done previously in case of reducing sugar. The endpoint was also indicated by the brick red colour precipitates. Titre value was used to calculate the percentage of total sugar using the formulae.

\subsubsection{Measurement of Reducing Sugar}

Reducing sugar content in canned litchi was estimated by Land and Eynon method as described by [19]. The sample extract filtrate was taken in burette and titrated against $4 \mathrm{ml}$ of boiling mixed Fehling's solution ( $2 \mathrm{ml}$ Fehling's solution A $+2 \mathrm{ml}$ Fehling's solution B) by using 2 - 3 drops of methylene blue as an indicator. The endpoint was indicated by the appearance of brick red colour precipitates. The formula was used for determining and the results expressed as percentage of reducing sugar in fruits.

\subsubsection{Measurement of Non-Reducing Sugar}

Non-reducing sugar content in canned litchi was calculated by subtracting reducing sugar from the total sugar content and expressed as percentage.

\subsubsection{Measurement of Ascorbic Acid}

Ascorbic acid content of canned litchi was determined according to the method described by [19]. The canned litchi aril juice of $10 \mathrm{~g}$ was taken and made up to a volume $100 \mathrm{ml}$ with $3 \%$ metaphosphoric acid $\left(\mathrm{HPO}_{3}\right)$ solution. The suspension 
was filtered by using Whatman No.1 filter paper. The 2, 6-dichlorophenol indophenol dye solution was standardized by titrating against standard ascorbic acid solution and the dye factor was calculated before actual titration. The sample juice of $5 \mathrm{ml}$ was taken from the filtrate and titrated against standardized dye solution through a burette till the pink colour was appeared as end point. Ascorbic acid content was calculated the formula and the results were expressed as $\mathrm{mg} / 100 \mathrm{~g}$ of pulp.

\subsubsection{Measurement of Total Phenolics Content}

The total phenolics content of canned litchi aril was determined using the FolinCiocalteu reagent as described by [20]. A sample of $0.5 \mathrm{ml}$ aliquot of extract was mixed with $2.5 \mathrm{ml}$ of Folin-Ciocalteu reagent (diluted tenfold) and allowed to react for 3 minutes at room temperature. Then, $2.5 \mathrm{ml}$ of sodium carbonate solution (7.5\%) and distilled water were added for a total of $8 \mathrm{ml}$. The reaction mixture was stored in the dark for 20 minutes at $25^{\circ} \mathrm{C}$. The absorbance was measured at $760 \mathrm{~nm}$ using a UV-2600 spectrophotometer (Shimadzu Inc., Kyoto, Japan). The calibration curve was plotted by preparing different concentration of 100, 200, 300, 400, 500 and $600 \mu \mathrm{g} / \mathrm{ml}$ Gallic acid solution, as performed for construction the calibration curve. The total phenolic content was determined by using the formula and the results were expressed in milligram equivalents of gallic acid (GAE) per $100 \mathrm{~g}$ of fresh sample (wb).

\subsubsection{Assay for Microbial Analysis}

Microbial examination was determined according to the [21]. The samples were taken and serial dilution was aseptically diluted up to $10^{-7}$ with sterile distilled water. The agar plates were prepared by pour plate method. Total viable count was determined with Plate Count Agar and the plates were incubated at $35^{\circ} \mathrm{C}$ for 48 h. Total yeasts and molds count were enumerated with Sabouraud Dextrose Agar. The plates were then incubated at $25^{\circ} \mathrm{C}$ for 5 days for yeast and mold. Microbial counts were expressed as base 10 logarithms of colony forming units per millilitre $(\log \mathrm{cfu} / \mathrm{ml})$.

\subsection{Statistical Analysis}

The collected data were statistically analyzed for analysis of variance (ANOVA) using Statistix version 8 software. The overall significance differences among the treatments were quantified by Least Significant Difference (LSD) test at $1 \%$ level ( $\mathrm{p} \leq 0.01)$ and $5 \%$ level $(\mathrm{p} \leq 0.05)$ of significance.

\section{Results and Discussion}

\subsection{Total Soluble Solid}

Total soluble solid (TSS) of canned litchi was no significant difference among the treatments during the storage periods (Table 1). This indicates that no significant changes of canned litchi in soluble solid content were observed along the storage periods which cannot happen fermentation process from the product 
and can maintain the quality of canned litchi. At an initial day of storage, the soluble solid content of fresh litchi $\left(16.24^{\circ} \mathrm{Brix}\right)$ was lower than all canned litchi processed in syrup. The value of soluble solid content $25.06{ }^{\circ}$ Brix and 24.48 ${ }^{\circ}$ Brix was recorded in untreated canned litchi at 15 and 90 days after storage. The value of soluble solid content $24.31^{\circ} \mathrm{Brix}$ and $24.89^{\circ} \mathrm{Brix}$ was recorded in $0.2 \%$ citric acid-treated in canned litchi, whereas $24.61^{\circ} \mathrm{Brix}$ and $23.97^{\circ} \mathrm{Brix}$ was recorded in $0.4 \%$ citric acid-treated in canned litchi at 15 and 90 days after storage. These values of soluble solid content result are considerably similar with [22] reported that all the pressurised fresh litchi $\left(16.3 \pm 1.79^{\circ} \mathrm{Brix}\right)$, litchi in syrup (22.6 $\left.{ }^{\circ} \mathrm{Brix}\right)$, pressurised syrup litchi $\left(22.8 \pm 0.47^{\circ} \mathrm{Brix}\right)$ and canned litchi $\left(23.9^{\circ} \mathrm{Brix}\right)$ had higher soluble solid contents than the fresh litchi $\left(11.2^{\circ} \mathrm{Brix}\right)$.

\subsection{Pulp Firmness}

Pulp firmness of canned litchi was no significant difference between treatments during the storage periods (Figure 1). On an initial day of storage, the texture of fresh litchi significantly decreased when the fresh litchi after preserved by canning.

Table 1. Total soluble solid of canned litchi as affected by syrup solution with different citric acid concentrations.

\begin{tabular}{cccccc}
\hline & \multicolumn{5}{c}{ Total soluble solid ( ${ }^{*}$ Brix) } \\
\cline { 2 - 6 } Treatment & \multicolumn{5}{c}{ days after storage } \\
\cline { 2 - 6 } & 16 & 15 & 30 & 60 & 90 \\
\hline Control & 16.24 & $25.06 \mathrm{a}$ & $25.13 \mathrm{a}$ & $25.72 \mathrm{a}$ & $24.48 \mathrm{a}$ \\
$0.2 \%$ citric acid & 16.24 & $24.31 \mathrm{a}$ & $24.65 \mathrm{a}$ & $25.18 \mathrm{ab}$ & $24.89 \mathrm{a}$ \\
$0.4 \%$ citric acid & 16.24 & $24.61 \mathrm{a}$ & $25.59 \mathrm{a}$ & $24.90 \mathrm{~b}$ & $23.97 \mathrm{a}$ \\
$\mathrm{LSD}_{0.05}$ & - & 1.25 & 1.20 & 0.73 & 2.04 \\
$\operatorname{Pr}>\mathrm{F}$ & - & $\mathrm{ns}$ & $\mathrm{ns}$ & $\mathrm{ns}$ & $\mathrm{ns}$ \\
$\mathrm{CV}(\%)$ & - & 2.93 & 2.75 & 1.67 & 4.82 \\
\hline
\end{tabular}

$\mathrm{ns}=$ non-significant; Means in the same column followed by the same letters are not significantly different at $\mathrm{p} \leq 0.05$.

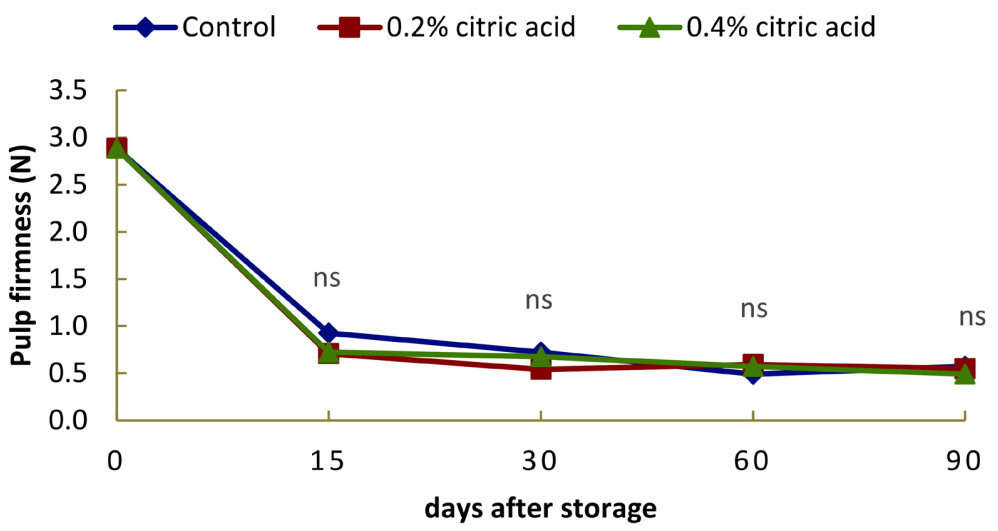

Figure 1. Effects of syrup solution with different citric acid concentrations on pulp firmness of canned litchi. 
This may be due to the pulp litchi treated with high temperature when processing. The pulp firmness value of fresh litchi was $2.88 \mathrm{~N}$ at initial day and the untreated canned litchi was $0.93 \mathrm{~N}$ at 15 days and $0.57 \mathrm{~N}$ at 90 days after storage. The pulp firmness value for $0.2 \%$ citric acid-treated in canned litchi was $0.71 \mathrm{~N}$ at 15 days and $0.55 \mathrm{~N}$ at 90 days after storage and then $0.4 \%$ citric acid-treated in canned litchi was $0.73 \mathrm{~N}$ at 15 days and $0.49 \mathrm{~N}$ at 90 days after storage. These results are different with [10] measured that the texture values of scoring system in canned litchi with different two cultivars of litchi and sugars content. This may be due to the different measuring method of texture and different cultivar in canned litchi.

\subsection{Pulp Colour}

The $\mathrm{a}^{\star}$ (red to green) value of canned litchi was no significant difference among the treatments at 15, 30 and 60 days after storage while there was highly significant difference at 90 days after storage (Figure 2). The untreated canned litchi was considerably the lowest $\mathrm{a}^{*}$ value, but it was higher $\mathrm{a}^{*}$ value at 15 days after storage than the other treatments and decreased at 30 days after storage and then increased gradually till the end of the storage. The canned litchi treated with $0.2 \%$ citric acid was lower $\mathrm{a}^{*}$ value than that of $0.4 \%$ citric acid. This means that increasing citric acid $(0.4 \%)$ added in canned litchi, caused more increasing in $\mathrm{a}^{\star}$ value. The lower $\mathrm{a}^{*}$ value indicated that none or the lesser amount of citric acid may be effective means of minimizing the pink discoloration with the lower in $\mathrm{a}^{\star}$ value. This result was agreed with [10] reported that the greater the amount of citric acid, the larger the $\mathrm{a}^{*}$ value in canned litchi was observed. The $\mathrm{a}^{*}$ value of canned litchi has a positive relation with the pink discolouration as described by [23]. [10] also described that the $a^{*}$ value evaluation represented the degree of pink discolouration.

\subsection{Total Titratable Acidity}

Total titratable acidity (TTA) of canned litchi was highly significant difference among the treatments throughout the storage periods (Table 2). The value of

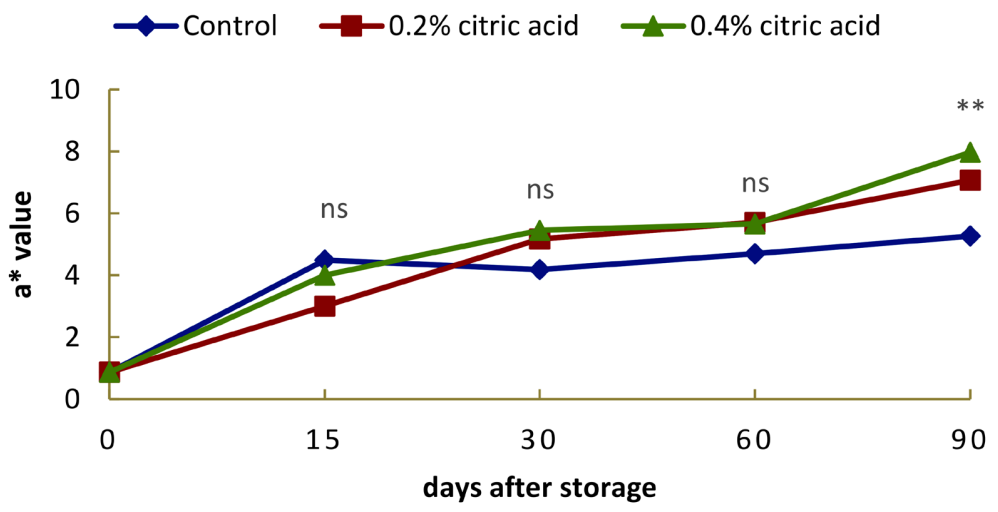

Figure 2. Effects of syrup solution with different citric acid concentrations on pulp colour $\left(\mathrm{a}^{\star}\right)$ of canned litchi. 
acidity content of fresh litchi was $0.46 \%$ at initial day and significantly decreased till 60 days after storage and then retained TTA percent at 90 days after storage. The acidity content of canned litchi treated with $0.4 \%$ citric acid was significantly the highest value $(0.30 \%)$ followed by canned litchi treated with $0.2 \%$ citric acid $(0.25 \%)$ along the storage periods. During the storage periods, the lowest value $(0.20 \%)$ in TTA was observed in the untreated canned litchi. The reason may be the increase in the amount of citric acid $(0.4 \%)$ can result in more acidity content of canned litchi. According to [24] stated that increase in acidity during storage could be possibly associated with the fermentation process of litchi juice.

\section{5. $\mathrm{pH}$}

The $\mathrm{pH}$ value of canned litchi was a highly significant difference among the treatments along the storage periods. The canned litchi processed in syrup containing $0.2 \%$ and $0.4 \%$ citric acid had lower $\mathrm{pH}$ values than the untreated canned litchi (without containing citric acid) (Figure 3). Unexpectedly, the untreated canned litchi maintained the $\mathrm{pH}$ value. However, canned litchi treated with $0.4 \%$

Table 2. Total titratable acidity of canned litchi as affected by syrup solution with different citric acid concentrations.

\begin{tabular}{cccccc}
\hline & \multicolumn{5}{c}{ Total titratable acidity (\%) } \\
\cline { 2 - 6 } Treatment & \multicolumn{5}{c}{ days after storage } \\
\cline { 2 - 6 } & 0 & 15 & 30 & 60 & 90 \\
\hline Control & 0.46 & $0.25 \mathrm{~b}$ & $0.21 \mathrm{c}$ & $0.20 \mathrm{c}$ & $0.20 \mathrm{c}$ \\
$0.2 \%$ citric acid & 0.46 & $0.28 \mathrm{~b}$ & $0.25 \mathrm{~b}$ & $0.25 \mathrm{~b}$ & $0.25 \mathrm{~b}$ \\
$0.4 \%$ citric acid & 0.46 & $0.35 \mathrm{a}$ & $0.35 \mathrm{a}$ & $0.30 \mathrm{a}$ & $0.30 \mathrm{a}$ \\
LSD & - & 0.04 & 0.04 & 0.03 & 0.02 \\
Pr $>\mathrm{F}$ & - & $* *$ & $* *$ & $* *$ & $* *$ \\
$\mathrm{CV}(\%)$ & - & 8.63 & 7.73 & 6.57 & 5.62 \\
\hline
\end{tabular}

$* *=$ significant level at $1 \%$; Means in the same column followed by the same letters are not significantly different at $\mathrm{p} \leq 0.05$.

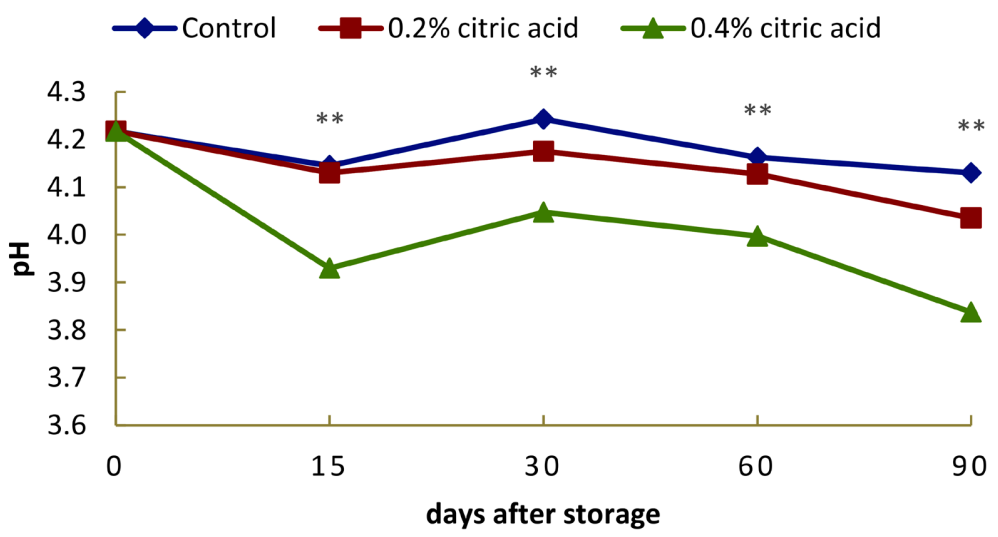

Figure 3. Effects of syrup solution with different citric acid concentrations on $\mathrm{pH}$ of canned litchi. 
citric acid had lower $\mathrm{pH}$ value than those of $0.2 \%$ citric acid till the end of the storage. This indicates that increase in amount of citric acid may cause more decrease in $\mathrm{pH}$ value. The $\mathrm{pH}$ value (4.22) of the initial day was higher than other days in canned litchi syrup. The highest $\mathrm{pH}$ value for the untreated canned litchi was 4.15 at 15 days and 4.13 at 90 days after storage, whilst the lowest $\mathrm{pH}$ value for $0.4 \%$ citric acid-treated in canned litchi was 3.93 at 15 days and 3.84 at 90 days after storage. The $\mathrm{pH}$ value for $0.2 \%$ citric acid-treated in canned litchi was 4.13 at 15 days and 4.04 at 90 days after storage. This result was agreed with [22] found that all litchi processed in syrup of pressurised fresh litchi (4.60 \pm 0.13$)$, litchi in syrup (4.22), pressurised syrup litchi $(4.25 \pm 0.10)$ and canned litchi (4.12) had lower $\mathrm{pH}$ values than the fresh litchi (4.72). According to the report by [10], the $\mathrm{pH}$ value of the Kwai-Wei litchi was 4.7 which was the lowest and the Sakan litchi had $5.5 \mathrm{pH}$ value, the highest value. The $\mathrm{pH}$ value of canned litchi (cv. Hau-yeh) was ranged between 4.35 - 3.86 and canned litchi (cv. No-mitzu) was ranged between $4.33-3.90 \mathrm{pH}$ value. The $\mathrm{pH}$ values of canned litchi (cv. Hau-yeh and cv. No-mitzu) with $0.2 \%$ citric acid added in syrup had higher $\mathrm{pH}$ value than $0.4 \%$ and $0.6 \%$ citric acid added in canned litchi at $26^{\circ} \mathrm{C} \pm$ $1^{\circ} \mathrm{C}$ for one year $[10]$.

\subsection{Total Sugar}

Total sugar of all canned litchi was no significant difference among the treatments during the storage periods (Table 3 ). The value of total sugar gradually decreased periodically along the storage days. On an initial day of storage, the value of the total sugar content of fresh litchi was $18.22 \%$. Total sugar of canned litchi treated with $0.2 \%$ citric acid was the highest value (14.51\%) and the lowest value $(13.77 \%)$ was observed in $0.4 \%$ citric acid-treated in canned litchi. In this result, total sugar content of all canned litchi decreased gradually till the end of the storage. According to [25] proposed that the increase in total sugars could be result of hydrolysis of polysaccharides like pectin, cellulose and starch into simple

Table 3. Total sugar of canned litchi as affected by syrup solution with different citric acid concentrations.

\begin{tabular}{cccccc}
\hline & \multicolumn{5}{c}{ Total sugar (\%) } \\
\cline { 2 - 6 } Treatment & \multicolumn{5}{c}{ days after storage } \\
\cline { 2 - 6 } & $\mathbf{0}$ & $\mathbf{1 5}$ & $\mathbf{3 0}$ & 60 & 90 \\
\hline Control & 18.22 & $17.97 \mathrm{a}$ & $17.65 \mathrm{a}$ & $16.82 \mathrm{a}$ & $14.25 \mathrm{a}$ \\
$0.2 \%$ citric acid & 18.22 & $17.81 \mathrm{a}$ & $17.06 \mathrm{a}$ & $16.09 \mathrm{a}$ & $14.51 \mathrm{a}$ \\
$0.4 \%$ citric acid & 18.22 & $17.44 \mathrm{a}$ & $17.13 \mathrm{a}$ & $15.92 \mathrm{a}$ & $13.77 \mathrm{a}$ \\
LSD $_{0.05}$ & - & 0.94 & 0.97 & 1.93 & 2.18 \\
Pr $>\mathrm{F}$ & - & $\mathrm{ns}$ & $\mathrm{ns}$ & $\mathrm{ns}$ & $\mathrm{ns}$ \\
$\mathrm{CV}(\%)$ & - & 3.05 & 3.23 & 6.86 & 8.90 \\
\hline
\end{tabular}

ns = non-significant; Means in the same column followed by the same letters are not significantly different at $\mathrm{p} \leq 0.05$. 
sugars in most fruit juice.

\subsection{Reducing Sugar}

Reducing sugar of canned litchi was no significant difference among the treatments at 15, 30 and 60 days after storage. However, there was highly significant difference between treatments at 90 days after storage (Table 4). On initial day of storage, the value of reducing sugar content of fresh litchi was $7.10 \%$. Among the treatment, canned litchi treated with $0.2 \%$ citric acid was observed the highest value $(7.88 \%)$ reducing sugar content followed by $(7.28 \%)$ canned litchi treated with $0.4 \%$ citric acid. The lowest value $(6.40 \%)$ reducing sugar content was observed in the untreated canned litchi at 90 days after storage. In this result, the value of reducing sugar content of $0.2 \%$ and $0.4 \%$ citric acid-treated in canned litchi increased during the storage periods. According to [25] described an increase in reducing sugar during storage may be due to the gradual conversion of non-reducing sugar and acids into reducing sugars in cashew apple juice.

\subsection{Non-Reducing Sugar}

Non-reducing sugar of all canned litchi was no significant difference between treatments during the storage periods (Table 5). At an initial day of storage, the value of non-reducing sugar content of fresh litchi was $11.12 \%$. The value of non-reducing sugar content $9.65 \%$ and $7.85 \%$ was recorded in untreated canned litchi at 15 and 90 days after storage. The value of non-reducing sugar content $9.00 \%$ and $6.62 \%$ was recorded in $0.2 \%$ citric acid-treated canned litchi, whereas $9.86 \%$ and $6.49 \%$ were recorded in $0.4 \%$ citric acid-treated in canned litchi at 15 and 90 days after storage. The untreated canned litchi was considerably the highest non-reducing sugar content. Moreover, $0.2 \%$ and $0.4 \%$ citric acid-treated in canned litchi were observed similar trends in non-reducing sugar content till the end of the storage.

Table 4. Reducing sugar of canned litchi as affected by syrup solution with different citric acid concentrations

\begin{tabular}{cccccc}
\hline & \multicolumn{5}{c}{ Reducing sugar (\%) } \\
\cline { 2 - 6 } Treatment & $\mathbf{5}$ & \multicolumn{5}{c}{ days after storage } \\
\cline { 2 - 6 } & $\mathbf{0}$ & $\mathbf{1 5}$ & $\mathbf{3 0}$ & $\mathbf{6 0}$ & $\mathbf{9 0}$ \\
\hline Control & 7.10 & 8.33 & 8.46 & 7.40 & $6.40 \mathrm{~b}$ \\
$0.2 \%$ citric acid & 7.10 & 8.81 & 8.41 & 8.79 & $7.88 \mathrm{a}$ \\
$0.4 \%$ citric acid & 7.10 & 7.58 & 8.74 & 8.14 & $7.28 \mathrm{a}$ \\
LSD $_{0.05}$ & - & 1.70 & 0.94 & 1.78 & 0.83 \\
Pr $>$ F & - & $\mathrm{ns}$ & $\mathrm{ns}$ & $\mathrm{ns}$ & $* *$ \\
$\mathrm{CV}(\%)$ & - & 11.88 & 6.36 & 12.70 & 6.71 \\
\hline
\end{tabular}

ns $=$ non-significant, ${ }^{* *}=$ significant level at $1 \%$; Means in the same column followed by the same letters are not significantly different at $\mathrm{p} \leq 0.05$. 


\subsection{Ascorbic Acid}

Ascorbic acid (vitamin C) of canned litchi was no significant difference among the treatments at 15, 30 and 60 days after storage. There was a highly significant difference at 90 days after storage (Table 6). The value of vitamin $\mathrm{C}$ content of fresh litchi was $32.00 \mathrm{mg} / 100 \mathrm{~g}$ on initial day. The value of vitamin $\mathrm{C}$ content $20.72 \mathrm{mg} / 100 \mathrm{~g}$ was observed in canned litchi treated by citric acid $0.2 \%$ and $0.4 \%$ at 90 days after storage. The untreated canned litchi at 90 days after storage was the lowest ascorbic acid content $(13.44 \mathrm{mg} / 100 \mathrm{~g})$ and it was due to untreated citric acid. On initial day of storage, the vitamin $\mathrm{C}$ content of fresh litchi considerably decreased after preservation of fresh litchi by canning. This is due to vitamin $\mathrm{C}$ is heat sensitive and decreased in vitamin $\mathrm{C}$ content during the processing period by high temperature and thus storage time affects vitamin $\mathrm{C}$ content as reported by [26]. Ascorbic acid content of canned litchi was no major changes up to 60 days after storage. However, $0.2 \%$ and $0.4 \%$ citric acid-treated

Table 5. Non-reducing sugar of canned litchi as affected by syrup solution with different citric acid concentrations.

\begin{tabular}{cccccc}
\hline & \multicolumn{5}{c}{ Non-reducing sugar (\%) } \\
\cline { 2 - 6 } Treatment & $\mathbf{5}$ & $\mathbf{5}$ & days after storage \\
\cline { 2 - 6 } & 11.12 & 9.65 & 9.19 & 9.42 & 7.85 \\
\hline Control & 11.12 & 9.00 & 8.65 & 7.30 & 6.62 \\
$0.2 \%$ citric acid & 11.12 & 9.86 & 8.39 & 7.78 & 6.49 \\
$0.4 \%$ citric acid & - & 1.84 & 1.35 & 3.43 & 2.53 \\
LSD & - & $\mathrm{ns}$ & $\mathrm{ns}$ & $\mathrm{ns}$ & $\mathrm{ns}$ \\
Pr $>\mathrm{F}$ & - & 11.18 & 8.92 & 24.29 & 20.91 \\
\hline $\mathrm{CV}(\%)$ & & &
\end{tabular}

$\mathrm{ns}=$ non-significant; Means in the same column followed by the same letters are not significantly different at $\mathrm{p} \leq 0.05$.

Table 6. Ascorbic acid of canned litchi as affected by syrup solution with different citric acid concentrations.

\begin{tabular}{cccccc}
\hline & \multicolumn{5}{c}{ Vitamin C content (mg/100g) } \\
\cline { 2 - 5 } Treatment & 0 & 15 & 30 & 60 & 90 \\
\cline { 2 - 5 } & 32.00 & $12.04 \mathrm{a}$ & $13.44 \mathrm{a}$ & $10.92 \mathrm{a}$ & $13.44 \mathrm{~b}$ \\
Control & 32.00 & $12.32 \mathrm{a}$ & $14.28 \mathrm{a}$ & $11.48 \mathrm{a}$ & $20.72 \mathrm{a}$ \\
$0.2 \%$ citric acid & 32.00 & $14.00 \mathrm{a}$ & $12.60 \mathrm{a}$ & $12.04 \mathrm{a}$ & $20.72 \mathrm{a}$ \\
$0.4 \%$ citric acid & - & 4.59 & 3.14 & 2.10 & 4.02 \\
LSD 0.05 & - & $\mathrm{ns}$ & $\mathrm{ns}$ & $\mathrm{ns}$ & $* *$ \\
Pr $>\mathrm{F}$ & - & 20.72 & 13.5 & 10.60 & 12.69 \\
CV $(\%)$ & & &
\end{tabular}

ns $=$ non-significant, ${ }^{*}=$ significant level at $1 \%$; Means in the same column followed by the same letters are not significantly different at $\mathrm{p} \leq 0.05$. 
in canned litchi were highly increased in ascorbic acid at 90 days after storage. According to [24] mentioned an if decrease in the ascorbic acid content of litchi fruit juice during the passage of storage duration might be due to the interaction effect of light, metallic ions and prevailing high temperature which had resulted in oxidation of ascorbic acid to dehydroascorbic acid. In this study, an increase in ascorbic acid was found in canned litchi during storage that had not resulted from ascorbic acid oxidation.

\subsection{Total Phenolics Content}

The total phenolics content of canned litchi aril increased during the storage periods. There was no significant difference at 15 days after storage. However, there was a highly significant difference at 30,60 and 90 days after storage (Figure 4). At an initial day of storage, the total phenolics content of fresh litchi increased after the preservation of fresh litchi by canning. The untreated canned litchi was no major changes along the storage periods and it was observed the lowest value of total phenolics content. $0.2 \%$ citric acid-treated in canned litchi exhibited more total phenolics content than that of $0.4 \%$ citric acid-treated canned litchi. At an initial day of storage, the value of total phenolics content of fresh litchi was $11.89 \mathrm{mg} \mathrm{GAE} / 100 \mathrm{~g}$. The lowest value of total phenolics content for the untreated canned litchi was $18.49 \mathrm{mg} \mathrm{GAE} / 100 \mathrm{~g}$ at 15 days and $19.55 \mathrm{mg}$ $\mathrm{GAE} / 100 \mathrm{~g}$ at 90 days after storage, whilst the highest value was $19.15 \mathrm{mg}$ $\mathrm{GAE} / 100 \mathrm{~g}$ at 15 days and $23.02 \mathrm{mg} \mathrm{GAE} / 100 \mathrm{~g}$ at 90 days after storage of total phenolics content was observed in canned litchi treated by $0.2 \%$ citric acid. According to [27] described that the total phenolics content of homogenized for canned longan (47.69 $\pm 8.46 \mathrm{mg} \mathrm{GAE} / 100 \mathrm{~g})$, canned litchi $(51.80 \pm 17.63 \mathrm{mg}$ $\mathrm{GAE} / 100 \mathrm{~g})$ and canned rambutan $(27.53 \pm 6.46 \mathrm{mg} \mathrm{GAE} / 100 \mathrm{~g})$.

\subsection{Microbial Analysis}

Total viable count, yeasts and molds were totally absent in all canned litchi processed in syrup during the advancement of the storage periods. The reason

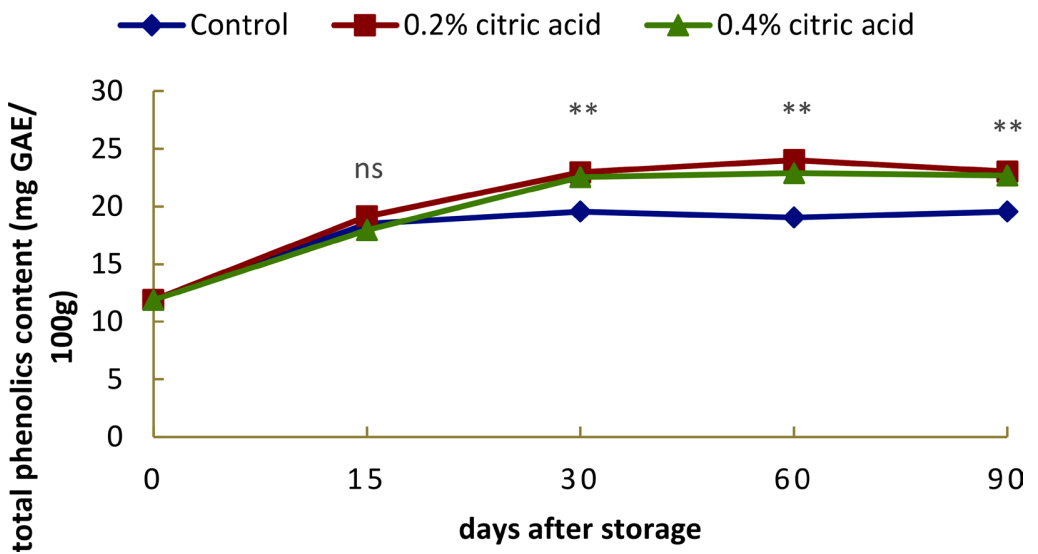

Figure 4. Effects of syrup solution with different citric acid concentrations on total phenolics content of canned litchi. 
may be caused by canned litchi processed by high temperature with tight hermetically sealed containers leading to inhibit microbial contamination. Moreover, the canned litchi was processed by the thermal pasteurization in boiling water for 18 minutes, which was affected on the inactivation of microorganisms. This result is different from [21] evaluated microbial analysis in canned products from purchased markets. The total viable count (TVC) was detected up to the level of $1.43-2.40 \mathrm{log} \mathrm{cfu} / \mathrm{g}$ and a load of total yeasts and molds count (TYM) was counted to the level of $1.0-1.85 \mathrm{log} \mathrm{cfu} / \mathrm{g}$ in finished products of canned orange, grapefruit, peach, pineapple, cocktail and cherry. The highest number of TVC and TYM was detected in a canned cocktail. However, coliforms, Clostridium spp., Staphylococcus aureus and Escherichia coli were totally absent in all canned fruits. [28] stated that the microbial contamination can occur at any step from production to consumption but the microbial growth during storage depends on the quality of packaging, storage temperature and preservatives added. [29] suggested that the desirable fungal count in all products should be in the order of $10^{3}-10^{5}(\mathrm{cfu} / \mathrm{ml})$.

\section{Conclusions}

Organic acid like citric acid has been tested for the preservation of canned litchi due to the good additive, safety and preventing food spoilage. This study has shown that the untreated canned litchi in $\mathrm{a}^{*}$ (red to green) value was more effective in minimising pink discolouration than $0.2 \%$ citric acid-treated in canned litchi. There were no changes in all canned litchi on pulp firmness and total soluble solid during the storage periods. Moreover, there was no significant difference between treatments on total sugar and non-reducing sugar in canned litchi along the storage periods. The untreated canned litchi can be maintained the $\mathrm{pH}$ value, whilst canned litchi treated with $0.2 \%$ citric acid exhibited more total phenolics content, $\mathrm{pH}$ value and reducing sugar content than those of $0.4 \%$ citric acid-treated canned litchi. However, $0.4 \%$ citric acid-treated in canned litchi was observed the highest total titratable acidity. Similar trends were seen in ascorbic acid from $0.2 \%$ and $0.4 \%$ citric acid-treated in canned litchi. The expected total viable count, yeasts and molds were not found in all canned litchi during the advancement of the storage periods.

These findings indicated that the untreated and $0.2 \%$ citric acid-treated canned litchi can well retain fresh quality, safety and preservation of canned litchi products stored at room temperature for about three months. Canned litchi treated with $0.2 \%$ of citric acid should be used to preserve litchi fruits on a commercial scale due to the highest in reducing sugar and total phenolics content with good pulp quality.

\section{Acknowledgements}

The author is grateful to Indo-Myanmar: Advanced Center for Agricultural Research and Education (ACARE), Yezin Agricultural University, Naypyitaw, 
Myanmar for providing laboratory facilities and financial support during the research work. The author is also thankful to supervisor, Head of Department of Food Science and Technology for her technical support, valuable suggestions and critical check to improve my research. Moreover, I would like to thanks to Head of Department of Postharvest Technology, ACARE for his administrative support and encouragement.

\section{Conflicts of Interest}

The authors declare no conflicts of interest.

\section{References}

[1] Menzel, C. (2001) The Physiology of Growth and Cropping in Lychee. Acta Horticulturae, 558, 175-184. https://doi.org/10.17660/ActaHortic.2001.558.24

[2] Yi, G.J., Wang, X.B. and Huo, H.Q. (2002) The Litchi Industry Status in China and Its Export Strategies. Journal of Fruit Science, 19, 188-190.

[3] Altendorf, S. (2018) Minor Tropical Fruits (Mainstreaming a Niche Market). Food Outlook, 67-75.

http://www.fao.org/fileadmin/templates/est/COMM_MARKETS_MONITORING/ Tropical_Fruits/Documents/Minor_Tropical_Fruits_FoodOutlook_1_2018.pdf

[4] Reyes, A., Castillo, J.F., Montiel, R.G.C. and Carrillo, M.L. (2016) Phenolic Content and Antioxidant Activity in Litchi Fruit (Litchi chinensis Sonn.) Pericarp. Jokull Journal, 66, 63-73.

[5] Prakash, K.S., Bashir, K. and Mishra, V. (2017) Development of Synbiotic Litchi Juice Drink and Its Physiochemical, Viability and Sensory Analysis. Journal of Food Processing and Technology, 8, Article ID: 1000708.

[6] Vijayanand, P., Kulkarni S.G. and Prathibha G.V. (2010) Effect of Pectinase Treatment and Concentration of Litchi Juice on Quality Characteristics of Litchi Juice. Journal of Food Science and Technology, 47, 235-239. https://doi.org/10.1007/s13197-010-0023-3

[7] Sivakumar, D. and Korsten, L. (2011) 15-Litchi (Litchi chinensis Sonn.). Postharvest Biology and Technology of Tropical and Subtropical Fruits, 3, 361-407, 408e-409e. https://doi.org/10.1533/9780857092885.361

[8] Singh, G., Nath, V., Pandey, S.D., Ray, P.K. and Singh, H.S. (2012) The Litchi. FAO of United Nations, New Delhi.

[9] Zhao, L., Hu, Z.Y., Yu, X.L. and Wu, Z.X. (2014) Processed Products from Litchi and Longan and Their Processing Technology in China. Acta Horticulturae, 1029, 379-384. https://doi.org/10.17660/ActaHortic.2014.1029.48

[10] Wu, M.C. and Chen, C.S. (1999) Effect of Sugar Types and Citric Acid Content on the Quality of Canned Lychee. Journal of Food Quality, 22, 461-469. https://doi.org/10.1111/j.1745-4557.1999.tb00178.x

[11] Hwang, L.S. and Cheng, Y.C. (1986) Pink Discoloration in Canned Lychee. Roles of Chemistry in the Quality of Processed Foods, 7, 96-107.

[12] Chakraborty, S., Rodriguez, R., Sampathu, S.R. and Saha, N.K. (1974) Prevention of Pink Discolouration in Canned Litchi (Litchi chinensis Sonn.). Journal of Food Science and Technology, 11, 226-228.

[13] Sommers, C.H., Fan, X.T., Handel, A.P. and Sokorai, K.B. (2003) Effect of Citric Acid on the Radiation Resistance of Listeria monocytogenes and Frankfurter Quali- 
ty Factors. Meat Science, 63, 407-415.

https://doi.org/10.1016/S0309-1740(02)00100-6

[14] Yang, C., Chen, T., Shen, B., Sun, S., Song, H., Chen, D. and Xi, W. (2019) Citric Acid Treatment Reduces Decay and Maintains the Postharvest Quality of Peach (Prunus persica L.) Fruit. Food Science \& Nutrition, 7, 3635-3643.

https://doi.org/10.1002/fsn3.1219

[15] Jiang, Y., Fu, J., Zauberman, G. and Fuchs, Y. (1999) Purification of Polyphenol Oxidase and the Browning Control of Litchi Fruit by Glutathione and Citric Acid. Journal of the Science of Food and Agriculture, 79, 950-954.

https://doi.org/10.1002/(SICI)1097-0010(19990515)79:7<950::AID-JSFA289>3.0.CO $\underline{; 2-\mathrm{E}}$

[16] Santerre, C.R., Cash, J. N. and Vannorman, D.J. (1988) Ascorbic Acid/Citric Acid Combinations in the Processing of Frozen Apple Slices. Journal of Food Science, 53, 1713-1716. https://doi.org/10.1111/j.1365-2621.1988.tb07823.x

[17] Jiang, Y.M., Pen, L.T. and Li, J.R. (2004) Use of Citric Acid for Shelf Life and Quality Maintenance of Fresh-Cut Chinese Water Chestnut. Journal of Food Engineering, 63, 325-328.

[18] Zhao, Z.H., Liu, M.J., Liu, P., Liu, X.Y., Dai, L., Yang, L. and Tian, S.L. (2009) Effects of Citric Acid Treatments on the Postharvest Fruit Quality of Ziziphus jujuba Mill. 'Linyilizao'. Acta Horticulturae, 840, 513-516. https://doi.org/10.17660/ActaHortic.2009.840.72

[19] Ranganna, S. (1986) Handbook of Analysis and Quality Control of Fruit and Vegetable Products. 2nd Edition, Tata McGrow-Hill Education, New York.

[20] Singleton. V.L., Orthofer, R. and Lamuela-Raventos, R.M. (1999) Analysis of Total Phenols, Other Oxidation Substances and Antioxidants by Means of Folin-Ciocalteu Reagent. Methods in Enzymology, 299, 152-178. https://doi.org/10.1016/S0076-6879(99)99017-1

[21] Shokr, A.A., El-Wafai, N.A., Mohamed, G.M. and Mahgoub, S.A.M. (2016) Evaluation of Microbial Load in Some Canned Fruits and Line Processing of Canned Orange. Zagazig Journal of Agricultural Research, 43, 1233-1244. https://doi.org/10.21608/zjar.2016.100491

[22] Phunchaisri, C. and Apichartsrangkoon, A. (2005) Effects of Ultra-High Pressure on Biochemical and Physical Modification of Lychee (Litchi chinensis Sonn.). Food Chemistry, 93, 57-64. https://doi.org/10.1016/j.foodchem.2004.10.001

[23] Cheng, Y.C. and Hwang, L.S. (1984) Studies on the Red Discoloration of Canned Lychee: 2. Discussion on the Pigment of Red Discoloration. Food Science, 11, 134-144.

[24] Kumar, S. and Kaur, R. (2019) Studies the Shelf life of Litchi (Litchi chinensis Sonn.) Juice as a Function of Preservation Methods. Journal of Emerging Technologies and Innovative Research, 6, 36-42.

[25] Singh, K. and Mathur, P.B. (1983) Studies in the Cold Storage of Cashew Apple. Indian Journal of Horticulture, 40, 115-121.

[26] Heldman, D.R. and Singh, R.P. (1981) Food Process Engineering. AVI Publishing Company, New York.

[27] Yahya, H.M., Roger, W.A. and Haron, H. (2017) Total Phenolic Content and Antioxidant Capacity of Selected Canned Fruits. Journal of Agricultural Science, 9, 96-101.

[28] Singh, S.K. and Sharma, M. (2017) Review on Biochemical Changes Associated with Storage of Fruit Juice. International Journal of Current Microbiology and Applied 
Sciences, 6, 236-245. https://doi.org/10.20546/ijcmas.2017.608.032

[29] Rahman, T., Hasan, S. and Noor, R. (2011) An Assessment of Microbiological Quality of Some Commercially Packed and Fresh Fruit Juices Available in Dhaka City: A Comprehensive Study. Stamford Journal of Microbiology, 1, 13-18. 